\title{
Genetic Distances between Two Echiuran Populations Discriminated by PCR
}

\author{
$\dagger$ Jong-Man Yoon \\ Dept. of Aquatic Life Medicine, College of Ocean Science and Technology, Kunsan National University, \\ Gunsan 54150, Korea
}

\begin{abstract}
Genomic DNA extracted from representatives of two populations, Gunsan and Chinese, of Urechis spp. was amplified using PCR with several primers. The band-sharing (BS) value between individuals no. 05 from the Gunsan population and no. 22 from the Chinese population was 0.206, which was the lowest recognized value. Oligonucleotides primer OPC-04 revealed 44 unique loci, which distinguished the Chinese population. Primer OPB-17 allowed the discovery of 22 loci shared by the two populations, which were present in all samples. Based on the average BS results, individuals from the Gunsan population demonstrated lower BS values $(0.661 \pm 0.012)$ than did those from the Chinese population $(0.788 \pm 0.014$; $p<0.05)$. The shortest genetic distance (GD) displaying a noteworthy molecular difference was between individuals CHINESE no. 12 and no. 13 (GD=0.027). Individual no. 06 from the Gunsan population was most distantly related to CHINESE no. 22 $(\mathrm{GD}=0.703)$. A group tree of the two populations was constructed by UPGMA Euclidean GD analysis based on a total of 543 fragments generated using six primers. The explicit markers recognized in this study will be used for genetic analysis, as well as to evaluate the species security and proliferation of echiuran individuals in intertidal regions of the Korean Peninsula.
\end{abstract}

Key words : Echiuran, Euclidean genetic distance, Hierarchical polar dendrogram, Similarity matrix, Urechis spp.

\section{INTRODUCTION}

Urechis species are marine animals belonging to the family Echiuridae, order Echiurida, and are widely distributed on the coast of the Yellow Sea, the southern sea of the Korean Peninsula, as well as in some parts of Japan, China, and the Pacific. In natural environments, Urechis spp. dwell in holes in a soft silt-clay sediment and gunk in the intertidal zone, where bivalves, crabs, and other crustaceans are abundant. Urechis spp. inhabit sandy mud caves of the U-type at certain depths. These echiurans are long- and soft-bodied animals. Despite their conservation and systematic diversity, little information is currently available regarding reproductive, biochemical, and environmental characteristics of Urechis species in Korea. Among Urechis spp., which can be discriminated reproductively (Choi et al., 1999; Shin \& Kim, 2002), biochemically (Lee et al., 1998, 1999; Choi et al., 2017; Oh \& Park, 2018), as well as environmentally (Choi et al., 1999, 2017; Kim, 2014), only few were examined at the genetic and/or molecular biological levels, unlike other invertebrates and/or teleost species. Thus, it is necessary to study genetic characteristics and the structure of echiuran populations to assess their genetic differences. Detailed

\footnotetext{
Manuscript received October 15, 2019, Received in revised form October 22, 2019, Accepted November 6, 2019

${ }^{\dagger}$ Corresponding Author : Jong-Man Yoon, Dr. Prof., Dept. of Aquatic Life Medicine, College of Ocean Science and Technology, Kunsan National University, Gunsan 54150, Korea. Tel.: +82-63-469-1887, E-mail: jmyoon@kunsan.ac.kr
}

This is an Open Access article distributed under the terms of the Creative Commons Attribution Non-Commercial License (http:// creative-commons.org/licenses/by-nc/3.0) which permits unrestricted non-commercial use, distribution, and reproduction in any medium, provided the original work is properly cited. 
information on genetic markers specific to lines, breeds, species, and/or geographical populations has been used for the identification and discrimination of individuals and populations, as well as hybrid pedigrees, and for molecular genetic testing (Mamuris et al., 1999; Klinbunga et al., 2000a; Nozaki et al., 2000; Yoon \& Park, 2002; Kim et al., 2004; Park et al., 2005; Yoon \& Kim, 2010; Yoon et al., 2012; Song \& Yoon, 2013; Oh \& Yoon, 2014). Accordingly, adaptations of PCR methods to the mariculture and fishing industry have been used to estimate genetic distances (GDs) among some finfish species and/or invertebrate animals from different geographical locations (Callejas \& Ochando, 1998; Tassanakajon et al., 1998; Klinbunga et al., 2000b; McCormack et al., 2000; Yoon \& Park, 2002; Kim et al., 2004; Park et al., 2005; Song \& Yoon, 2013; Oh \& Yoon, 2014). In this study, to evaluate the GDs and dissimilarities between geographical echiuran populations, clustering analysis of two Urechis spp. populations, from Gunsan and a Chinese coastal region, respectively, was performed.

\section{MATERIALS AND METHODS}

Experimental specimens were collected individually from Gunsan and Chinese Urechis spp. populations. Body muscle samples from 22 individuals, which were anesthetized with MS 222 (100 ppm), were taken from the body trunk and placed into pasteurized vials. The bodies of these Urechis spp. echiurans were collected into sterile tubes, which were immediately placed on ice and then stored in a refrigerator until use. DNA extraction was performed as described previously (Oh \& Yoon, 2014). Chloroform $(500 \mu \mathrm{L})$ was added to the mixture, and the content of the tube was mixed by inversion. After washing, samples of body muscle tissues were placed into $10-\mathrm{mL}$ test tubes, to which three volumes of lysis buffer were added, and the content of the tubes was mixed by gentle inversion. The precipitates collected were incubated with $20 \mu \mathrm{L}$ of a proteinase $\mathrm{K}$ solution $(15 \mathrm{mg} / \mathrm{mL})$. After the incubation, $300 \mu \mathrm{L}$ of $6 \mathrm{M} \mathrm{NaCl}$ was added, and the mixture was gently pipetted for a few minutes. The DNA pellets were dried for $3 \mathrm{~h}$, then stored at $-90^{\circ} \mathrm{C}$ until use, and thawed in TE buffer. The purified genomic DNA was quantified by measuring absorbance at $260 \mathrm{~nm}$ using a spectrophotometer (Beckman Coulter, Buckinghamshire, UK). The DNA tablets were then dried for more than $10 \mathrm{~h}$, stored at $-90^{\circ} \mathrm{C}$ until use, and thawed in purified DW.

Oligonucleotides primers were purchased from Operon Technologies, USA. OPA-17 (5'-GACCGCTTGT-3'), OPB20 (5'-GGACCCTTAC-3'), OPC-01 (5'-TTCGAGCCAG3'), OPC-04 (5'-CCGCATCTAC-3'), OPC-09 (5'-CTCAC CGTCC-3'), and OPD-05 (5'-TGAGCGGACA-3') were used to reveal unique loci to each population and shared loci between the two Urechis spp. populations. These oligonucleotides primers were used to determine genetic variations, DNA polymorphisms, and pairwise similarities between Urechis spp. from Gunsan and the Chinese location. PCR was performed using a programmable DNA thermal cycler (MJ Research, Inc., Waltham, MA, USA). DNA amplification was carried out in $25-\mu \mathrm{L}$ reactions, which contained $10 \mathrm{ng}$ of template DNA, $22 \mu \mathrm{L}$ of a premix (Bioneer Corp., Daejeon, Korea), and 1 unit of a primer. Amplified fragments were separated by electrophoresis in agarose (Bioneer Corp.) gels with TBE using a 100-bp DNA ladder (Bioneer Corp.) as a DNA molecular weight marker, followed by staining with ethidium bromide. The electrophoresed agarose gels were illuminated with UV light, and photographs were taken using a PhotoMan direct copy system (PECA Products, Beloit, WI, USA).

A similarity matrix comprising band-sharing (BS) values was designed, along with the presence/absence of amplified fragments at specific spots in identical gels from DNA frameworks. BS values were estimated according to Jeffreys \& Morton (1987) and Yoke-Kqueen \& Radu (2006). Based on comparison of two lanes, the BS value was calculated as follows: $\mathrm{BS}=2(\mathrm{Nab}) /(\mathrm{Na}+\mathrm{Nb})$, where $\mathrm{Nab}$ is 
the number of fragments shared by samples a and $\mathrm{b}$; $\mathrm{Na}$ is the total number of fragments in sample $\mathrm{a}$; and $\mathrm{Nb}$ is the total number of fragments in sample b. The average within-population similarity was assessed by pairwise comparison between individuals within a population. The relationship between unlike individuals in the Urechis spp. populations was estimated, along with the BS values and similarity matrix. A hierarchical polar dendrogram was constructed using similarity matrices to produce a group tree using Systat version 10 (SPSS, Inc., Chicago, IL, USA). The Systat software was also used to evaluate GDs, Euclidean GDs within and between the Urechis spp. populations, means, standard errors, and $t$-test values.

\section{RESULTS AND DISCUSSION}

In this study, six oligonucleotides primers, OPA-17, OPB-20, OPC-01, OPC-04, OPC-09, and OPD-05, were utilized to identify unique loci to each population and shared loci between the two Urechis spp. populations. The complexity of the banding patterns varied significantly between primers to two regions. The number of fragments in each size interval was computed by combining fragments obtained with all six oligonucleotides primers, as shown in Fig. 1. The sizes of the DNA fragments also varied greatly, from 50 to 2,050 bp, as displayed in Fig. 1. Fragments $>2,100$ bp were not detected in the two Urechis spp. populations. A cluster tree for the two Urechis spp. populations was built using UPGMA Euclidean GD analysis based on 543 fragments generated by using the six oligonucleotides primers. In finfish, a phylogenetic tree was constructed using UPGMA cluster analysis based on 3,744 distinguishable fragments from gynogenetic clones of the silver crucian carp, Carassius auratus gibelio Block (Zhou et al., 2000). The sizes of fragments varied from 220 to $1,700 \mathrm{bp}$ in four species from the Mullidae family (Mamuris et al., 1999). DNA fragments obtained using four primers ranged from 100 to $2,300 \mathrm{bp}$ in the brittle star (Amphiura filiformis) (McCormack et al., 2000). In this study, the average number of distinct fragments was 25.67 per primer in the Chinese echiuran population, while the number of recorded fragments varied from 7 to 12 per primer in four species from the Mullidae family (Mamuris et al., 1999).

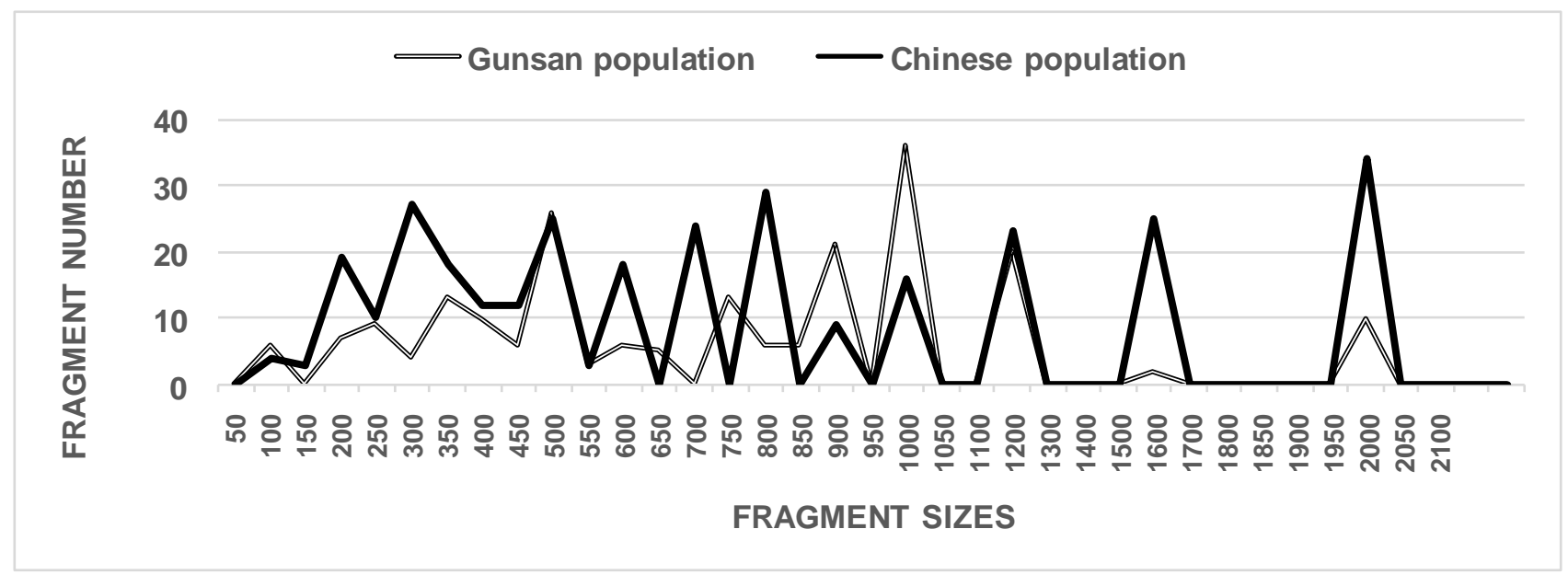

Fig. 1. Distribution of fragments of different sizes, amplified from representatives of the Gunsan and Chinese populations of Urechis spp. Gray line: Gunsan population; black line: Chinese population. The number of fragments in each size interval was calculated by combining fragments for all six oligonucleotides primers. Larger fragments $(>2,100 \mathrm{bp})$ were not detected in the two Urechis spp. populations. 
The BS value between individuals no. 05 from the Gunsan population and no. 22 from the Chinese population of Urechis spp. was 0.206 , which was the lowest observed value, as illustrated in Table 1 . The BS value between individual's no. 17 and no. 18 was 0.939 , which was the highest value, discovered within the Chinese Urechis spp. population. Twenty-two unique loci were found in the Gunsan Urechis spp. population using the OPA-17 oligonucleotides primer, as summarized in Table 2. Remarkably, oligonucleotides primers OPC-04 and OPB20 revealed 44 and 33 unique loci in the Chinese Urechis spp. population, respectively (Table 2 ), which were able to distinguish the two populations. Notably, primer OPB-17 allowed the detection of 22 shared loci between the two populations, which were present in all samples, as summarized in Table 2. Oligonucleotides primer OPD-05

Table 1. Similarity matrix of the band-sharing values obtained for the Gunsan and Chinese Urechis spp. populations

\begin{tabular}{|c|c|c|c|c|c|c|c|c|c|c|c|c|c|c|c|c|c|c|c|c|c|c|}
\hline \multicolumn{23}{|c|}{ Band-sharing values } \\
\hline & \multicolumn{11}{|c|}{ From Gunsan } & \multicolumn{11}{|c|}{ From the Chinese } \\
\hline & 1 & 2 & 3 & 4 & 5 & 6 & 7 & 8 & 9 & 10 & 11 & 12 & 13 & 14 & 15 & 16 & 17 & 18 & 19 & 20 & 21 & 22 \\
\hline 1 & - & 0.610 & 0.650 & 0.670 & 0.587 & 0.670 & 0.727 & 0.689 & 0.601 & 0.622 & 0.598 & 0.335 & 0.297 & 0.305 & 0.306 & 0.384 & 0.344 & 0.328 & 0.381 & 0.360 & 0.428 & 0.297 \\
\hline 2 & & - & 0.803 & 0.665 & 0.543 & 0.795 & 0.554 & 0.741 & 0.597 & 0.800 & 0.642 & 0.265 & 0.265 & 0.241 & 0.238 & 0.300 & 0.243 & 0.269 & 0.282 & 0.271 & 0.255 & 0.267 \\
\hline 3 & & & - & 0.713 & 0.618 & 0.775 & 0.637 & 0.722 & 0.593 & 0.714 & 0.608 & 0.244 & 0.244 & 0.220 & 0.296 & 0.322 & 0.267 & 0.283 & 0.324 & 0.311 & 0.273 & 0.284 \\
\hline 4 & & & & - & 0.792 & 0.723 & 0.521 & 0.714 & 0.651 & 0.621 & 0.504 & 0.306 & 0.273 & 0.285 & 0.315 & 0.324 & 0.311 & 0.292 & 0.396 & 0.295 & 0.333 & 0.312 \\
\hline 5 & & & & & - & 0.668 & 0.565 & 0.754 & 0.707 & 0.724 & 0.464 & 0.317 & 0.287 & 0.286 & 0.271 & 0.273 & 0.243 & 0.237 & 0.305 & 0.283 & 0.297 & 0.206 \\
\hline 6 & & & & & & - & 0.589 & 0.735 & 0.623 & 0.619 & 0.699 & 0.261 & 0.261 & 0.236 & 0.253 & 0.375 & 0.278 & 0.278 & 0.347 & 0.317 & 0.340 & 0.312 \\
\hline 7 & & & & & & & - & 0.694 & 0.636 & 0.706 & 0.587 & 0.258 & 0.285 & 0.252 & 0.271 & 0.337 & 0.238 & 0.236 & 0.260 & 0.297 & 0.297 & 0.721 \\
\hline 8 & & & & & & & & - & 0.693 & 0.917 & 0.721 & 0.267 & 0.268 & 0.328 & 0.310 & 0.269 & 0.271 & 0.296 & 0.900 & 0.325 & 0.276 & 0.248 \\
\hline 9 & & & & & & & & & - & 0.652 & 0.509 & 0.248 & 0.248 & 0.228 & 0.220 & 0.275 & 0.242 & 0.254 & 0.356 & 0.271 & 0.287 & 0.278 \\
\hline 10 & & & & & & & & & & - & 0.633 & 0.307 & 0.307 & 0.287 & 0.293 & 0.324 & 0.313 & 0.335 & 0.442 & 0.364 & 0.354 & 0.332 \\
\hline 11 & & & & & & & & & & & - & 0.317 & 0.317 & 0.302 & 0.289 & 0.445 & 0.337 & 0.300 & 0.293 & 0.290 & 0.339 & 0.345 \\
\hline 12 & & & & & & & & & & & & - & 0.933 & 0.880 & 0.865 & 0.676 & 0.685 & 0.772 & 0.807 & 0.792 & 0.788 & 0.574 \\
\hline 13 & & & & & & & & & & & & & - & 0.815 & 0.915 & 0.750 & 0.685 & 0.782 & 0.710 & 0.832 & 0.796 & 0.692 \\
\hline 14 & & & & & & & & & & & & & & - & 0.796 & 0.698 & 0.629 & 0.677 & 0.813 & 0.756 & 0.743 & 0.611 \\
\hline 15 & & & & & & & & & & & & & & & - & 0.780 & 0.767 & 0.802 & 0.807 & 0.851 & 0.812 & 0.755 \\
\hline 16 & & & & & & & & & & & & & & & & - & 0.881 & 0.795 & 0.832 & 0.839 & 0.784 & 0.730 \\
\hline 17 & & & & & & & & & & & & & & & & & - & 0.939 & 0.884 & 0.885 & 0.847 & 0.827 \\
\hline 18 & & & & & & & & & & & & & & & & & & - & 0.899 & 0.899 & 0.862 & 0.843 \\
\hline 19 & & & & & & & & & & & & & & & & & & & - & 0.918 & 0.871 & 0.807 \\
\hline 20 & & & & & & & & & & & & & & & & & & & & - & 0.937 & 0.806 \\
\hline 21 & & & & & & & & & & & & & & & & & & & & & - & 0.821 \\
\hline 22 & & & & & & & & & & & & & & & & & & & & & & - \\
\hline
\end{tabular}


Genetic Distances between Two Echiuran Populations

Table 2. Numbers of unique loci to each population and of shared loci between the Gunsan and Chinese populations of Urechis spp., obtained by DNA analysis using six oligonucleotides primers

\begin{tabular}{cccc}
\hline \multirow{2}{*}{ Primer } & \multicolumn{2}{c}{ No. of unique loci to each population } & $\begin{array}{c}\text { No. of shared loci between } \\
\text { the two populations }\end{array}$ \\
\cline { 2 - 4 } & Gunsan & Chinese & 22 \\
OPA-17 & 22 & 11 & 0 \\
OPB-20 & 11 & 33 & 0 \\
OPC-01 & 11 & 11 & 0 \\
OPC-04 & 0 & 44 & 0 \\
OPC-09 & 0 & 22 & 22 \\
\hline OPD-05 & 22 & 33 & 44 \\
\hline Tverage no. per primer & 66 & 154 & 7.33 \\
\hline
\end{tabular}

also allowed the discovery of 22 shared loci between the two Urechis spp. populations, with major and/or minor fragments of 1,200 bp present in all samples. The average number of unique loci was found to be 2.5 times higher in the Chinese than in the Gunsan population. A total of 271 unique loci, with an average of 38.7 loci per primer, were identified in the GSCP population. Furthermore, 33 loci, with an average of 4.7 loci per primer, were found to be shared by three hard clam (Meretrix lusoria) populations (Yoon et al., 2012). A decamer primer, BION-B14, revealed seven unique loci, with fragments of approximately $100 \mathrm{bp}$, which were able to distinguish each population of Vietnamese cuttle fish (Sepia esculenta) (Yoon \& Kim, 2010). Remarkably, 21 unique loci were detected using the BION-B06 primer, with fragments of approximately 100, 450, and $650 \mathrm{bp}$, in a Sockcho cuttlefish population.

The average BS value was lower $(p<0.05)$ for individuals from the Gunsan population $(0.661 \pm 0.012)$ than for those from the Chinese population $(0.788 \pm 0.014)$, as demonstrated in Table 3. Meanwhile, the average BS value in this study was higher than that between the common carp and Israeli carp species $(0.57 \pm 0.03)$ (Yoon, 2001) and in a Geojedo oyster population $(0.537 \pm 0.017)$ (Kim et al., 2004). However, the average BS value in this study was similar to that in the Spanish barbel species (0.71-0.81) (Callejas \& Ochando, 1998). In terms of average BS values, a cuttlefish ( $S$. esculenta) population from Sockcho exhibited a higher BS value (0.826) than did fish from Seocheon (0.465) (Yoon $\&$ Kim, 2010). Polymorphisms are determined based on banding patterns of primer-amplified products at specific sites (Mamuris et al., 1999; Klinbunga et al., 2000a; Nozaki et al., 2000; Yoon, 2001; Yoon \& Park, 2002; Kim et al., 2004; Oh \& Yoon, 2014). Several studies have reported the sizes of PCR fragments for black tiger shrimp (Penaeus monodon) (Tassanakajon et al., 1998), the brittle

Table 3. Estimates of average band-sharing values (mean \pm SE) between the two Urechis spp. populations, based on the band-sharing values and similarity matrix

\begin{tabular}{ccc}
\hline \hline Population & Gunsan & Chinese \\
\hline Gunsan & $0.661 \pm 0.012^{\mathrm{a}}$ & $0.304 \pm 0.007^{\mathrm{b}}$ \\
Chinese & - & $0.788 \pm 0.014^{\mathrm{c}}$ \\
\hline${ }^{\mathrm{a}-\mathrm{c}}$ Values with different superscript letters are significantly \\
different $(p<0.05)$.
\end{tabular}

Each value represents three independent experiments. 


\section{Cluster Tree}

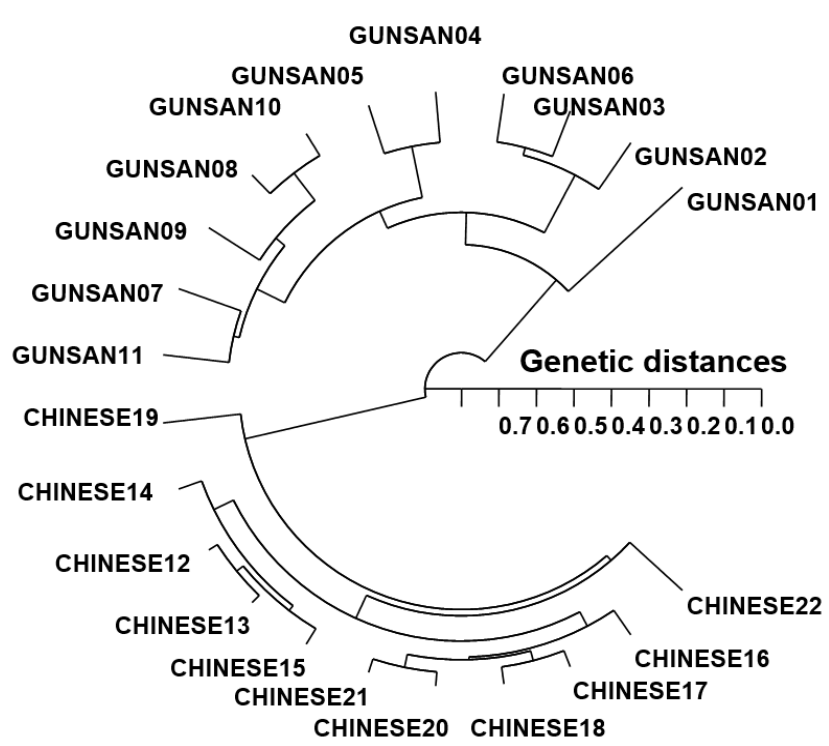

Fig. 2. Hierarchical polar dendrogram of genetic distances for two geographical populations of Urechis spp., Gunsan (GUNSAN 01-11) and Chinese (CHINESE 12-22), respectively. The relationships between dissimilar individuals in the Urechis spp. populations were elucidated, along with the band-sharing values and similarity matrix.

star (A. filiformis) (McCormack et al., 2000), and lobster species (Park et al., 2005). Unambiguous data, resulting from variations in DNA polymorphisms, were found to be meaningful in the identification of individuals and/or populations (Tassanakajon et al., 1998; Mamuris et al., 1999; Yoon \& Park, 2002; Chenyambuga et al., 2004; Kim et al., 2004; Yoon \& Kim, 2010; Yoon et al., 2012; Song \& Yoon, 2013).

In this study, PCR led to the discovery of a significant GD between the two populations/species. PCR enabled the discrimination of the populations/species and the detection of genetic variations within the two geographical populations of Urechis spp. The hierarchical polar dendrogram delineated two main groups, group 1 (GUNSAN 01-11) and group 2 (CHINESE 12-22), within the two geographical Urechis spp. populations. The shortest GD (0.027), exhibiting a significant molecular difference, was found between individuals CHINESE no. 12 and no. 13 . Meanwhile, individual GUNSAN no. 06 of Urechis spp. was most distantly related to CHINESE no. 22 (GD=0.703). These results demonstrated that the Gunsan Urechis spp. population was genetically different from the Chinese Urechis spp. population. A neighbor-joining tree constructed based on GDs among populations, using a PCR method, was used to clarify the relationships between three mud crab species (Klinbunga et al., 2000b). The results showed that there were great genetic differences between geographically separated populations within a species and between species. Phylogenetic relationships among five Haliotis species and one hybrid were elucidated by calculating distance coefficients and constructing a phylogenetic tree based on PCR data (Kim et al., 2000). These species were divided into two clusters, of which cluster I included H. discus hannai, H. discus, H. gigantea, H. sieboldii, and the hybrid and was further divided into two subclusters. Subsequently, these authors reported that PCR was a preferred tool for determining phylogenetic relationships among six Haliotis species.

As mentioned above, the prospect of PCR analysis to detect diagnostic markers for the identification of the two Urechis spp. populations was recognized, confirming that the technique is a suitable approach for DNA assessments, both within and between individuals, populations, and species. The classification of echiuran species is based on morphological variations in the body size, body type, body color, body wall, proboscis type, and proboscis size. It has been presumed that differences in these traits between species reflect their separate origin or genetic identity (Chenyambuga et al., 2004). Information on GDs among echiurans would be beneficial to comprehend the expansion or maintenance of individual populations in inshore and tidal flat regions of the Korean Peninsula. However, additional research, using more individuals, populations, species, and genera, as well as more primers, will be needed to fully elucidate the specificity of loci to definite 
taxa and subsequently explore the interspecific gene flow in the genus Urechis. Further studies including larger numbers of samples and primers need to be conducted to obtain more detailed information on the genetic structure of the two species of echiurans.

\section{ORCID}

Jong-Man Yoon

https://orcid.org/0000-0003-2825-681X

\section{CONFLICT OF INTEREST}

The author declares no potential conflict of interest.

\section{AUTHOR CONTRIBUTIONS}

The article is prepared by a single author.

\section{ETHICS APPROVAL}

This article does not require IRB/IACUC approval because there are no human and animal participants.

\section{REFERENCES}

Callejas C, Ochando MD (1998) Identification of Spanish barbel species using the RAPD technique. J Fish Biol 53:208-215.

Chenyambuga SW, Hanotte O, Hirbo J, Watts PC, Kemp SJ, Kifaro GC, Gwakisa PS, Petersen PH, Rege JEO (2004) Genetic characterization of indigenous goats of sub-Saharan Africa using microsatellite DNA markers. Asian-Aust J Anim Sci 17:445-452.

Choi SD, Kim HJ, Rha SJ, Hong SY, Lee WK, Lee WB (1999) The effect of $\mathrm{pH}$ and salinity on egg development of Urechis unicinctus (von Drasche) in southern Korea. J Aqua 12:155-161.

Choi TB, Rha SJ, Yun SK, Yu TS, Choi SD (2017) The effect of 6 Amino acids on larval settlement Urechis unicinctus. J Fish Mar Sci Educ 29:1799-1807.

Jeffreys AJ, Morton DB (1987) DNA fingerprints of dogs and cats. Anim Genet 18:1-15.

Kim DK (2014) A study on the spatial distribution and the habitat environment of Urechis unicinctus (von Drasche) in the intertidal zone of Taean in the central Yellow Sea, Korea. M.S. Thesis, Kunsan Nat'l University, p 48.

Kim JY, Park CY, Yoon JM (2004) Genetic differences and DNA polymorphism in oyster (Crassostrea spp.) analysed by RAPD-PCR. Korean J Genet 26:123-134.

Kim SK, Jung YH, Han SH, Oh YS, Ko MH, Oh MY (2000) Phylogenetic relationship among Haliotis spp. distributed in Korea by the RAPD analysis. Korean J Genet 22:43-49.

Klinbunga S, Ampayup P, Tassanakajon A, Jarayabhand P, Yoosukh W (2000a) Development of species-specific markers of the tropical oyster (Crassostrea belcheri) in Thailand. Mar Biotechnol 2:476-484.

Klinbunga S, Boonyapakdee A, Pratoomchat B (2000b) Genetic diversity and species-diagnostic markers of mud crabs (Genus Scylla) in Eastern Thailand determined by RAPD analysis. Mar Biotechnol 2:180-187.

Lee JY, Ryu HS, Moon JH, Suh JS (1998) Chemical composition of glycoprotein from Urechis unicinctus. $\mathrm{J}$ Korean Soc Food Sci Nutr 28:285-291.

Lee JY, Ryu HS, Moon JH, Suh JS (1999) Antitumor effect and immunological activity of glycoprotein from Urechis unicinctus. J Korean Soc Food Sci Nutr 28:917-923.

Mamuris Z, Stamatis C, Bani M, Triantaphyllidis C (1999) Taxonomic relationships between four species of the Mullidae family revealed by three genetic methods: Allozymes, random amplified polymorphic DNA and mitochondrial DNA. J Fish Biol 55:572-587. 
McCormack GP, Powell R, Keegan B (2000) Comparative analysis of two populations of the brittle star Amphiura filiformis (Echinodermata:Ophiuroidea) with different life history strategies using RAPD markers. Mar Biotechnol 2:100-106.

Nozaki T, Mishiba K, Mii M, Koba T (2000) Construction of synteny groups of Brassica alboglabra by RAPD markers and detection of chromosome aberrations and distorted transmission under the genetic background of B. campestris. Theor Appl Genet 101:538-546.

Oh H, Yoon JM (2014) Genetic distances of three mollusk species investigated by PCR analysis. Dev Reprod 18:43-49.

Oh HY, Park NG (2018) Isolation of an invertebrate-type lysozyme from the body wall of spoon worm, Urechis unicinctus. J Life Sci 28:300-306.

Park SY, Park JS, Yoon JM (2005) Genetic differences and variations in slipper lobster (Ibacus ciliatus) and deep sea lobster (Puerulus sewelli) determined by RAPD analysis. Korean J Genet 27:307-317.

Shin KS, Kim WJ (2002) Fine structural study of coelomic solitary spermatogenesis in Urechis unicinctus. Korean J Electron Microsc 32:107-119.

Song YJ, Yoon JM (2013) Genetic differences of three Pollicipes mitella populations identified by PCR analysis. Dev Reprod 17:199-205.

Tassanakajon A, Pongsomboon S, Jarayabhand P, Klinbunga
S, Boonsaeng VV (1998) Genetic structure in wild populations of black tiger shrimp (Penaeus monodon) using randomly amplified polymorphic DNA analysis. J Mar Biotechnol 6:249-254.

Yoke-Kqueen C, Radu S (2006) Random amplified polymorphic DNA analysis of genetically modified organisms. J Biotechnol 127:161-166.

Yoon JM (2001) Genetic similarity and difference between common carp and Israeli carp (Cyprinus carpio) based on random amplified polymorphic DNAs analyses. Korean J Biol Sci 5:333-339.

Yoon JM, Park HY (2002) Genetic similarity and variation in the cultured and wild crucian carp (Carassius carassius) estimated with random amplified polymorphic DNA. Asian-Australas J Anim Sci 15:470-476.

Yoon JM, Kim JY (2010) Genetic differences and geographic variation in cuttle fish (Sepia esculenta Hoyle). Dev Reprod 14:163-170.

Yoon JM, Park KI, Choi SH (2012) Variation of shell color in three geographic white clam (Meretrix lusoria) populations of the Yellow Sea. Dev Reprod 16:47-51.

Zhou L, Wang Y, Gui JF (2000) Analysis of genetic heterogeneity among five gynogenetic clones of silver crucian carp, Carassius auratus gibelio Block, based on detection of RAPD molecular markers. Cytogenet Cell Genet 88:133-139. 